\title{
Initiation of Human Immunodeficiency Virus Type 1 (HIV-1) Transcription is Inhibited by Noncytolytic $\mathrm{CD8}^{+}$Suppression
}

\author{
R. Glenn Overman ${ }^{1, \S}$, Anthony L. Llorens ${ }^{3, \S}$, Michael L. Greenberg ${ }^{6}$, Mariano A. Garcia-Blanco ${ }^{3,4}$ \\ and Georgia D. Tomaras ${ }^{*}, 1,2,4$
} Departments of ${ }^{1}$ Surgery, ${ }^{2}$ Immunology, ${ }^{3}$ Medicine, ${ }^{4}$ Molecular Genetics and Microbiology, Duke University Medical
Center, Durham, NC, USA, ${ }^{6}$ Trimeris, Inc., Morrisville, NC, USA

\begin{abstract}
The replication of human immunodeficiency virus type 1 (HIV-1) can be inhibited by noncytolytic CD $8^{+} \mathrm{T}$ cell mediated suppression, an immune response that specifically targets HIV-1 gene expression. Clinical studies demonstrate that this immune response may play an important role in the host defense against HIV infection. In this study, we examined the distinct steps in viral gene expression for inhibition by noncytolytic CD8 ${ }^{+} \mathrm{T}$ cells. A primary HIV-1 infection system of $\mathrm{CD}^{+}$enriched peripheral blood mononuclear cells was utilized to examine the HIV-1 life cycle as a relevant $e x$ vivo system. Established $\mathrm{CD}^{+} \mathrm{T}$ cell lines from two $\mathrm{HIV}^{+}$long-term nonprogressors were used to examine differences at the level of transcriptional initiation and elongation of the HIV genome. This infection system coupled with the results from real-time measurement of newly transcribed RNA transcripts determined that there was a significant decrease (5-8 fold) in short intracellular viral RNA transcripts. These data strongly favor a role for the initiation of virus transcription in noncytolytic $\mathrm{CD} 8^{+} \mathrm{T}$ cell mediated suppression.
\end{abstract}

\section{INTRODUCTION}

The concept of non-cytolytic $\mathrm{CD}^{+} \mathrm{T}$ cell mediated suppression of HIV-1 unfolded in a seminal study by Levy's group [1] that showed that $\mathrm{CD}^{+} \mathrm{T}$ lymphocytes can inhibit HIV replication in a dose dependent manner. This activity does not require HLA histocompatibility [2], is distinct from the cytolytic activity of $\mathrm{CD}^{+}$cells $[3,4]$ and is mediated by both cell contact and soluble molecules $[5,6]$. The potency of noncytolytic $\mathrm{CD}^{+} \mathrm{T}$ cell mediated activity from HIV infected individuals in vitro has been shown to inversely correlate with disease progression [7, 8]. Several studies have confirmed that the $\mathrm{CD} 8^{+} \mathrm{T}$ cell mediated activity positively correlates with a healthier clinical status [8-11]. In addition, a significant number of exposed uninfected individuals demonstrate noncytolytic $\mathrm{CD}^{+} \mathrm{T}$ cell mediated suppressive activity $[12,13]$. These clinical studies indicate that $\mathrm{CD} 8^{+} \mathrm{T}$ cell mediated antiviral activity may play an important role in the host defense against HIV infection and thus have a great potential to be of use in vaccination strategies. These results will contribute to the goal of identifying the specific antiviral mechanisms, and viral and cellular components, that contribute to the control of viremia by noncytolytic $\mathrm{CD}^{+} \mathrm{T}$ cell suppression.

The precise mechanism of $\mathrm{CD}^{+} \mathrm{T}$ cell mediated noncytolytic activity has not yet been fully delineated. The inhibition of virus replication can potentially take place at many different steps in the virus life cycle and therefore there is an array of molecules that may be the target of suppressive activity. It is known that for the inhibition of viral entry of CCR5-tropic viruses, the $\beta$-chemokines, MIP-1 $\alpha$, MIP-1 $\beta$,

*Address correspondence to this author at the Departments of Surgery, and Molecular Genetics and Microbiology, Rm. 205 SORF, LaSalle Street Ext., P.O. Box 2926, Duke University Medical Center, Durham, NC 27710, USA; Tel: (919) 681-5598; Fax: (919) 684-4288; E-mail: gdt@duke.edu

${ }^{\S}$ These authors contributed equally to this work. and RANTES, can inhibit HIV replication by competitive inhibition of virus-coreceptor binding and downregulation of coreceptor cell surface expression [14-16]. The activities of these $\beta$-chemokines appear to act at entry, and not HIV-1 gene expression [17]. In addition, several well-characterized molecules have been tested for their ability to recapitulate this activity, but none can fully account for either the potency of suppression or the breadth across CXCR4 and CCR5-tropic viral infections [6].

In studies to examine the ability of $\mathrm{CD}^{+} \mathrm{T}$ lymphocytes to act on viral gene expression, primary $\mathrm{CD}^{+} \mathrm{T}$ lymphocytes were transfected with LTR driven reporter constructs to measure the effects of $\mathrm{CD} 8^{+} \mathrm{T}$ cells on both basal and Tat mediated transcription of the HIV-1 LTR [18]. CD8 ${ }^{+} \mathrm{T}$ cells from asymptomatic HIV-1 infected individuals could inhibit both basal and Tat mediated transcription and other work further substantiated these findings [19, 20]. Importantly, these affects on viral gene expression were also observed and confirmed using a primary lymphocyte culture in an ongoing cycle of viral replication where potent suppression of CXCR4-tropic viruses was shown not to involve entry or reverse transcription [21]. In addition, noncytolytic $\mathrm{CD}^{+} \mathrm{T}$ cell mediated suppression does not target viral integration [22]. These studies, utilizing both reporter constructs and ongoing cycles of virus replication in primary lymphocytes, indicate that $\mathrm{CD} 8^{+} \mathrm{T}$ lymphocyte suppression occurs sometime between proviral integration and splicing. However, it was not clear at what stage of virus transcription the antiviral activity was targeting. Transcription of the viral genome involves a complex series of events that trigger the initiation of transcription by the assembly of factors at the viral promoter. Once the transcript is initiated, another series of molecular interactions between the viral RNA and RNA binding proteins trigger elongation of the viral transcript. Previous studies examining the mechanism of action of noncytolytic $\mathrm{CD}^{+} \mathrm{T}$ cells did not differentiate between initiation and elongation of virus transcription. Utilizing an approach that 
distinguishes the molecular events occurring during HIV transcription, we demonstrate that noncytolytic $\mathrm{CD}^{+} \mathrm{T}$ cell mediated suppression targets initiation of virus transcription, but does not significantly affect virus transcript elongation. In addition to providing a better understanding of the mechanism of $\mathrm{CD}^{+}$antiviral activity, the results presented here could lead to the design of novel therapeutics that specifically inhibit the initiation of viral RNA transcripts.

\section{MATERIALS AND METHODS}

Isolation and Preparation of Primary $\mathrm{CD8}^{+} \mathrm{T}$ lymphocytes. Peripheral blood mononuclear cells (PBMCs) were prepared from venous blood from a seronegative donor (nEW, HIV-1 Naïve CD8 ${ }^{+}$) by standard Ficoll-Hypaque density separation. PBMCs were activated for 3 days with antiCD3 (OKT3) and anti-CD28 antibodies at $37^{\circ} \mathrm{C}$ in a humidified $\mathrm{CO}_{2}$ incubator. $\mathrm{CD} 8^{+} \mathrm{T}$ cells were isolated by negative selection with anti-CD4 ${ }^{+}$antibody coated beads (Dynal, Lake Success, NY). $\mathrm{CD}^{+}$cells from two asymptomatic long-term nonprogressors (LTNP) (JRHVS CD8 ${ }^{+}$and HS HVS $\mathrm{CD}^{+}$) displaying potent suppressive activity for both $\mathrm{X} 4$ and R5 viruses were transformed with Herpesvirus saimiri (HVS) subgroup C strain 488-77 as previously described [24] and characterized [21]. IRB approval was obtained for all work with human specimens.

Pseudotyped Virus Production. Pseudotyped viruses were produced by transfection of DNA into the human embryonic kidney cell line, 293T, using FuGENE (Roche Inc.). The reporter virus DNA, pNL4-3.LUC.R $\mathrm{E}^{-}$[obtained through the NIH AIDS Research and Reference Reagent Program from Dr. Nathaniel Landau [25, 26] was cotransfected with the expression vector pNL4-3 env (a gift from Dr. T. Dragic). The virus-containing supernatants were harvested two days later, filtered through a $0.45 \mu \mathrm{m}$ membrane and stored at $-80^{\circ} \mathrm{C}$ in $20 \% \mathrm{v} / \mathrm{v}$ FBS. Viral tropism was tested in a human astroglioma cell line expressing either $\mathrm{CD}^{+}$alone (U87.CD4), CD4 ${ }^{+}$and CCR5 (U87.CD4.CCR5), or $\mathrm{CD}^{+}$and CXCR4 (U87.CD4.CXCR4) all obtained through the NIH AIDS Research and Reference Reagent Program from Drs. HongKui Deng and Dan Littman [27]. U87 cells were grown in DMEM L-glutamine containing $1 \%$ Pen/Strep, $15 \%$ FBS, and selective agents $(300 \mu \mathrm{g} / \mathrm{ml} \mathrm{G} 418$ for CD4 alone cell lines, or $300 \mu \mathrm{g} / \mathrm{ml} \mathrm{G} 418$ plus $1 \mu \mathrm{g} / \mathrm{ml}$ puromycin). In triplicate, U87 cells were seeded in a 96-well flat bottom plate at $7.5 \times 10^{3}$ cells/well and grown overnight at $37^{\circ} \mathrm{C}$. The selective media was then removed and $100 \mathrm{ul}$ of pseudotyped virus was added. Cells were infected for 2.5 hours at $37^{\circ} \mathrm{C} .100 \mathrm{ul}$ of fresh media without selective agents was then added.

To assess viral tropism, at 72 hours post-infection the media was removed and cells gently washed with warm PBS. U87 cells were then lysed with $50 \mu \mathrm{l}$ of $1 \mathrm{X}$ Cell Culture Lysis Reagent (Promega, Madison, WI) and then frozen for $>30 \mathrm{~min}$ at $-80^{\circ} \mathrm{C}$. $20 \mathrm{ul}$ of each lysate was assayed with the Promega Luciferase Assay System on an EG\&G (Berthhold) LB 96V luminometer and viral infection was measured in relative light units (RLU).

$\mathrm{CD8}^{+}$Suppression Assay. Suppression assays were performed as previously described [21] with modifications as indicated. Peripheral blood mononuclear cells were prepared from freshly drawn blood from a pool of $\mathrm{HIV}^{-}$donors and activated as described above. $\mathrm{CD}^{+}$and $\mathrm{CD}^{+}$enriched populations were obtained by negative selection with anti-CD8 ${ }^{+}$or anti-CD4 ${ }^{+}$antibody coated beads (Dynal, Lake Success, NY), respectively. $\mathrm{CD}^{+}$-enriched PBMC were infected with $1 \mathrm{ml}$ of pseudotyped virus per $1 \times 10^{6} \mathrm{CD} 4^{+}$cells in the presence of DEAE $(20 \mu \mathrm{g} / \mathrm{ml})$ for 2.5 hours at $37^{\circ} \mathrm{C}$. The cells were washed with PBS and resuspended at $4.5 \times$ $10^{5}$ cells per $\mathrm{ml}$ in AIM-V medium (Invitrogen, Carlsbad, CA) containing $20 \% \mathrm{v} / \mathrm{v}$ FBS and $40 \mathrm{U} / \mathrm{ml}$ IL-2. Previously enriched effector $\mathrm{CD}^{+}$cells from $\mathrm{LTNP}$ and $\mathrm{HIV}^{-}$donors were added at a $2: 1 \mathrm{E}: \mathrm{T}$ ratio achieving a final concentration of $1.35 \times 10^{6}$ cells $/ \mathrm{ml} .200 \mu \mathrm{l}$ aliquots of the infectious cultures, in triplicate, were transferred to a 96-well flat bottom microtiter plate and incubated at $37^{\circ} \mathrm{C}$ for $48 \mathrm{hrs}$.

At 48 hours post-infection, the cells used for RNA isolation were pelleted and resuspended in a 1:5 v/v PBS:RNAlater (Ambion, Austin TX) solution, stored at $4^{\circ} \mathrm{C}$ overnight, then transferred to $-20^{\circ} \mathrm{C}$. To assess infection, cultures in the microtiter plate were washed with PBS at 48 hours, lysed with 1X Cell Culture Lysis Reagent (Promega, Madison, WI) and then frozen for $>30 \mathrm{~min}$ at $-80^{\circ} \mathrm{C}$. $20 \mathrm{ul}$ of each lysate was assayed with the Promega Luciferase Assay System on an EG\&G (Berthhold) LB 96V luminometer. Luciferase activity was measured in relative light units (RLU).

Viral RNA Analysis. Total RNA, including low molecular weight RNA, was isolated from the RNAlater-stored cell samples using the mirVana miRNA Isolation Kit (Ambion) according to manufacturer's instruction. DNA was removed with a double DNase digest treatment using DNA-free (Ambion). The RNA samples were quantified using a spectrophotometer and then electrophoresed on a $1 \%$ agarose gel to check the integrity. Real-time PCR with HIV specific primers (HIV short-F and HIVshort-R) and host RPS9 specific primers (RPS9-F and RPS9-R1) was then performed to check for DNA contamination against a standard curve, described below. The DNA-free RNA was then reversetranscribed (Thermoscript, Invitrogen) using reverse primers (Table 1) at $119 \mathrm{bp}, \sim 2.9 \mathrm{~kb}, \sim 7.1 \mathrm{~kb}$, and a luciferase region $(9.7 \mathrm{~kb})$ of the pNL4-3.LUC.R ${ }^{-}$genome (GenBank Accession number AF324493.1).

Table 1.

\begin{tabular}{|c|c|c|}
\hline Primer & Sequence [5'to 3'] & $\begin{array}{c}\text { 5' Position } \\
\text { [bp] }\end{array}$ \\
\hline \hline HIVshortF & CCTGGGAGCTCTCTGGCTAA & 29 \\
\hline HIVshortR & AACAGACGGGCACACACTACTTT & 119 \\
\hline $3 \mathrm{~kb}-\mathrm{F}$ & CAATGACATACAGAAATTAGTGGGAAA & 2868 \\
\hline $3 \mathrm{~kb}-\mathrm{R}$ & CTTTGGTTCCCCTAAGAAGTTTACAT & 2958 \\
\hline 7kb-F & TGGCAGGAAGTAGGAAAAGCA & 7040 \\
\hline 7kb-R & AGCAGCCCAGTAATATTTGATGAAC & 7120 \\
\hline Luc-F & AGGTGGCTCCCGCTGAA & $* 9.6 \mathrm{~kb}$ \\
\hline Luc-R & ACACCTGCGTCGAAGATGTTG & $* 9.7 \mathrm{~kb}$ \\
\hline RPS9-F & GACGGGGAAGCGGAGCCAACA & $* * 308$ \\
\hline RPS9-R1 & GCTTCAGCTCTTGGTCGAGACGAG & $* * 418$ \\
\hline RPS9-R2 & GCGAGCGTGGTGGATGGACTTG & $* * 5579$ \\
\hline
\end{tabular}

*Primer locations are based on the luciferase gene sequence in Promega's pGL-3 basic vector, forward primer at $1343 \mathrm{bp}$ and reverse primer $1406 \mathrm{bp}$. The luciferase reporter gene is located in the nef gene of the HIV pNL4-3.LUC.R $\mathrm{E}^{-}$genome at $8.3 \mathrm{~kb}$. **Primer locations are based on Ensembl Gene ID: ENSG00000170889. 
Table 2.

\begin{tabular}{|c|c|c|}
\hline Primer & $\begin{array}{c}\text { Position mRNA } \\
\text { NM_001013 }\end{array}$ & $\begin{array}{c}\text { Position Genome } \\
\text { ENSG00000170899 }\end{array}$ \\
\hline \hline RPS9-F & 37 & 308 \\
\hline RPS9-R1 & 147 & 418 \\
\hline RPS9-R2 & 437 & 5579 \\
\hline
\end{tabular}

The RPS9 primers were designed based on GenBank Accession number U14971.1. The primer positions are listed in reference to the 5 ' base relative to ${ }^{+} 1$ transcription/gene start.

Host gene RPS9 primer locations were at 418 and 5579 bp (Ensembl Gene ID ENSG00000170889) (Tables 1,2). Transcript copy numbers for the above-mentioned locations were determined by real-time PCR on an ABI 7500 (Applied Biosystems, Foster City, CA) using SYBR Green PCR Master Mix (Applied Biosystems). A melting curve analysis was performed on each run to insure amplicon specificity. A standard curve (plasmid copy range $10^{2}-3 \times 10^{6}$ ) was generated using plasmid pNL4-3.LUC. $\mathrm{R}^{-}{ }^{-}$with primers specific to the $119 \mathrm{bp}$ region of interest. Acceptable slopes (M) for standard curves ranged from -3.1 to -3.6 (optimal slope, $M=$ -3.3 ). All best fit lines demonstrated $\mathrm{R}^{2}$ values $>0.98$. Note: all primers were designed to yield amplicons of analogous size, approximately $100 \mathrm{bp}$, and were chosen for similar amplification efficiencies. The RNA extracted from each viral infection experiment was reverse transcribed in duplicate, and cDNA from each of the duplicates was used in two separate real-time PCR experiments. The cDNA templates used in the real-time experiments were assayed in triplicate.

\section{RESULTS}

Noncytolytic $\mathrm{CD8}^{+}$T Cell Mediated Suppression System in $\mathrm{CD4}^{+} \mathbf{T}$ Lymphocytes. To examine the mechanism of noncytolytic $\mathrm{CD}^{+} \mathrm{T}$ cell mediated suppression during the time of viral gene expression, we utilized a single cycle infection assay in primary $\mathrm{CD}^{+}$lymphocytes. Two established cell lines (JR-HVS CD8 ${ }^{+}$and $\mathrm{HS}-\mathrm{HVS} \mathrm{CD}^{+}$) that mediate suppressive activity [21] were utilized to determine if viral RNA transcripts are inhibited at transcriptional initiation and/or elongation. In a manner analogous to the nontransformed cells from which they were derived, the HVStransformed CD8 cells were shown to potently inhibit infection of both X4- and R5- dependent viruses [21]. Here we utilize the $\mathrm{CD}^{+}$effectors and $\mathrm{CD}^{+}$targets that were previously determined by our group to lack any demonstrable cytolytic [21] and allogeneic reactivities. This system allows the isolated study of the effects of noncytolytic $\mathrm{CD}^{+}$suppression on HIV replication in a system where we have previously measured the kinetics of HIV entry, reverse transcription and early gene expression [21]. Fig. (1) shows the results of $\mathrm{CD}^{+}$suppression assays using a CXCR4-tropic enveloped (NL4-3) pseudotyped virus. The $\mathrm{CD}^{+}$effectors (JR HVS CD8 ${ }^{+}$and HS HVS CD8 ${ }^{+}$) demonstrated a greater than one-log reduction in viral infection in contrast to the HIV-1 naïve $\mathrm{CD} 8^{+}$cells ( $\mathrm{nEW} \mathrm{CD}^{+}$). We did note that there was more variation in the level of infection in the presence of the $\mathrm{nEW} \mathrm{CD} 8^{+}$cells, however the $\mathrm{CD} 8^{+}$cells derived from the $\mathrm{HIV}^{+}$LTNP significantly suppressed HIV replication compared to $\mathrm{nEW} \mathrm{CD}^{+}$cells.
Noncytolytic $\mathrm{CD8}^{+} \mathrm{T}$ Cell Mediated Suppression of HIV Gene Expression. To investigate the possible mechanisms of suppression at transcriptional initiation and elongation, we utilized a system that combines reverse transcription of viral RNA transcripts with quantitative real time PCR (adapted from [28]). RNA was isolated from the $\mathrm{CD}^{+}$suppression assays shown in Fig. (1). Reverse transcription was utilized to construct cDNAs, and then real-time PCR was used to quantify viral RNA transcripts at various points in the HIV genome. Fig. (2) shows the different regions of the HIV genome that were reverse transcribed and then quantified using real-time PCR. HIV RNA transcript copy numbers were measured by quantitative real-time PCR at the following positions along the HIV genome: 119 bp (HIV short-R and HIVshort-F primers), 2,958 bp (3 kb-R and $3 \mathrm{~kb}-\mathrm{F}$ ), 7,120 bp (7 kb-R and $7 \mathrm{~kb}-\mathrm{F}$ ), and 9,700 bp (Luc-R and LucF). All short and longer transcripts were reversed transcribed from the RNA template using primer sets that resulted in amplicons of similar size, "short amplicon", to accurately quantify and compare both long and short transcripts. Fig. (2) diagrams the RNA transcripts and PCR amplicons for both the short transcript that tests transcriptional initiation and also for one of the longer elongated transcripts $(3 \mathrm{~kb})$ as an example. Primers specific to a housekeeping gene, ribosomal protein (RPS9), were utilized at comparable positions on the gene as a control.

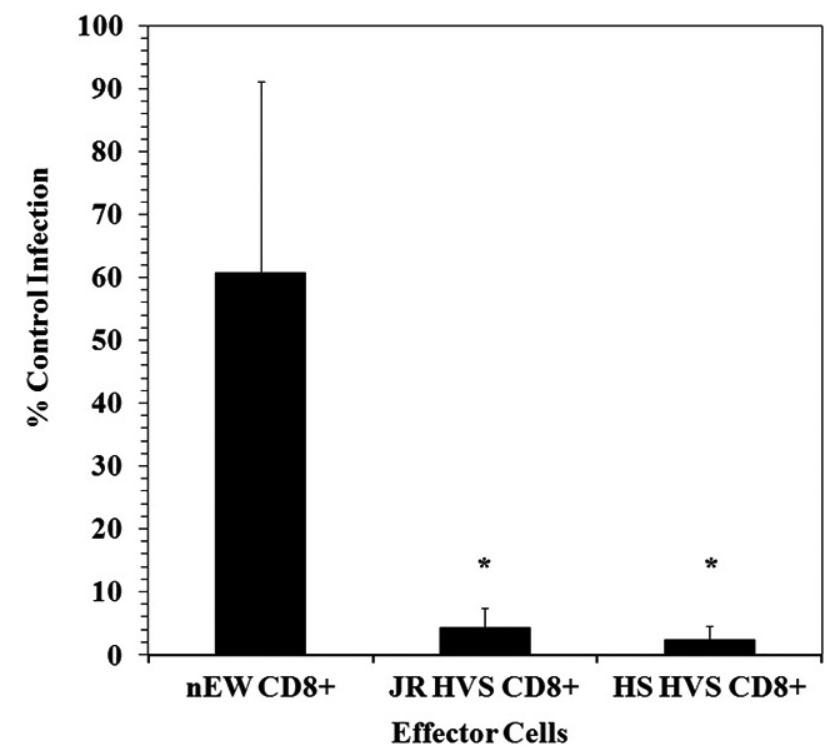

Fig. (1). Noncytolytic CD8 ${ }^{+} \mathrm{T}$ Cell Mediated Suppression of HIV NL4-3 Pseudotyped Virus Replication. $\mathrm{CD}^{+} \mathrm{T}$ lymphocytes were infected with NL4-3 pseudotyped virus and exposed to $\mathrm{CD}^{+} \mathrm{T}$ lymphocytes. $(\mathrm{N}=4) \%$ Control Infection is the amount of infection relative to the control NL4-3 infected $\mathrm{CD}^{+}$T-lymphoctyes. The cutoff for the upper limit for suppression was $10 \%$ infection, a 1$\log$ reduction, in the $\mathrm{CD}^{+}$co-cultures with JR HVS CD8 ${ }^{+}$and $\mathrm{HS}$ $\mathrm{HVS} \mathrm{CD}^{+}{ }^{*} \mathrm{p}=0.023$ for both JR and HS HVS CD8 ${ }^{+}$compared to nEW CD8 ${ }^{+}$, Student t-Test.

Viral Suppression by $\mathrm{CD8}^{+}$Cells Occurs at Initiation. To define whether or not suppression occurred at transcriptional initiation the initiation ratio of non-suppressed HIV short copy number to suppressed HIV short copy number [NSS/SS] was examined. The use of a single-cycle infection 


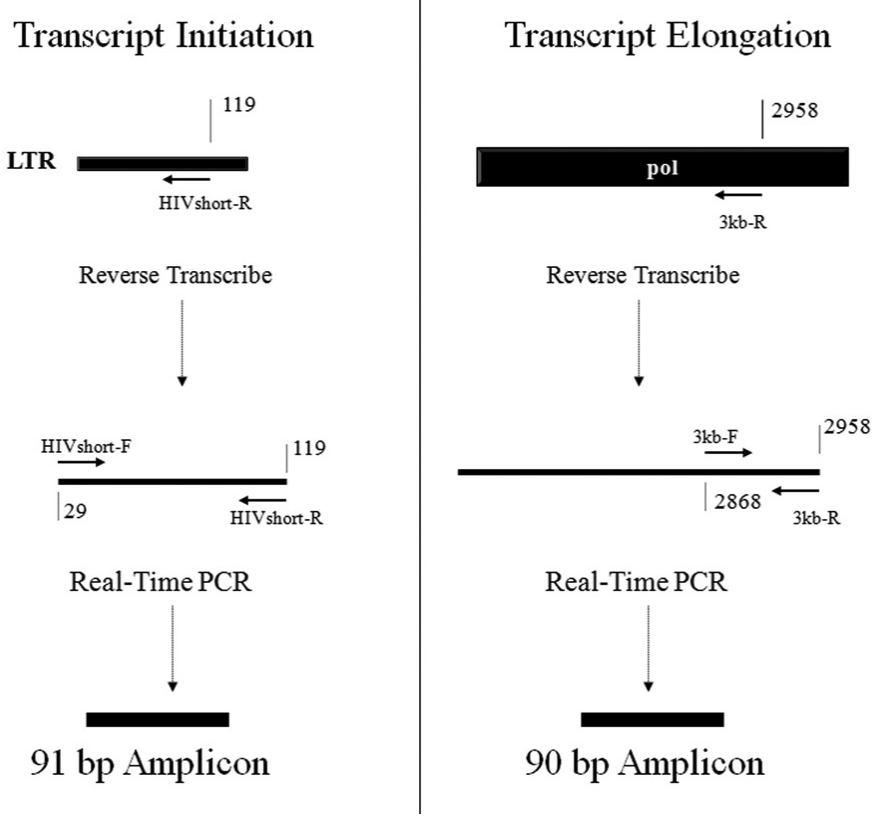

Fig. (2). Quantification of HIV RNA Transcripts from the HIV-1 Genome during Cellular Infection. Transcriptional initiation and elongation were examined using quantitative RT-PCR that measures RNA transcripts that reach a relatively short distance and also a much larger distance from the start of transcription. Reverse transcription was performed using primers near the LTR ("HIV short-R") and within the pol gene ("3kb-R"). The short and long transcripts were quantified using primer sets of equivalent efficiency that amplified transcripts of similar length ("HIV short-F and HIV short-R" for the short cDNA transcript and "3kb-F and 3kb-R" for the long cDNA transcript). Strategy adapted from Sune et al. [28].

prevented subsequent rounds of virus replication and allowed the observance of a single viral replication cycle. At 48 hours post infection, the initiation ratio demonstrated that the JR HVS CD8 ${ }^{+}$and HS HVS CD8 ${ }^{+}$cells executed significant suppression at the initiation stage of viral transcription, on average 7.3 fold and 5.1 fold inhibition respectively (Fig. 3). The HIV-naïve $\mathrm{CD}^{+}$cells also exhibited inhibition, 3.7 fold on average, albeit not to the strength of LTNP CD8 ${ }^{+}$ cells. Interestingly, this lower level of inhibition of initiation was consistent regardless of the level of infection in the presence of HIV-naïve $\mathrm{CD}^{+}$cells. Both the JR HVS $\mathrm{CD}^{+}$ and HS HVS CD $8^{+}$cells suppressed transcriptional initiation to a significantly higher level than the HIV-naïve $\mathrm{CD} 8^{+}$cells ( $p<0.001$ for both comparisons, Student's t-test).

The housekeeping gene, ribosomal protein S9 (RPS9), was measured to determine if the $\mathrm{CD}^{+}$cells had a general effect on suppressing host cell transcription. From the same RNA isolates for every experiment, real-time PCR was used to quantify early transcription of the housekeeping gene. The data as shown in Fig. (3) illustrates there was no suppression of the housekeeping gene, RPS9 supporting the finding that $\mathrm{CD}^{+} \mathrm{T}$ cell mediated suppression is unique to HIV transcription.

Measurement of Transcripts that have completed Elongation and Splicing. Primers specific to near the $3 \mathrm{~kb}$ site of the HIV genome were designed to address the question of whether noncytolytic $\mathrm{CD}^{+} \mathrm{T}$ cell mediated suppression affects transcriptional elongation. An equation NSL/[SL $\mathrm{x}$ [NSS/SS]] was derived so that any contributing factors from transcriptional initiation could be included. Fig. (4) shows data from HIV short and $3 \mathrm{~kb}$ primers with the resulted values of $\mathrm{JR}=0.6, \mathrm{HS}=0.6$, and $\mathrm{EW}=0.8$. The lack of significant effect (controlling for the suppressive effects at viral initiation) at approximately $3 \mathrm{~kb}$ from the start of viral transcription indicates that suppression of virus replication is likely limited to the initiation of transcription. In addition, RT-PCR was also used to quantify the late transcription products of the housekeeping gene, RPS9. There was no significant effect on RPS9 elongation. Because both RPS9 transcriptional initiation and elongation are both near a 1:1 ratio between non-suppressed and suppressed systems, this supports that there is no global effect of $\mathrm{CD} 8^{+}$inhibition on general host cell gene expression. This supports previous data that non-cytolytic $\mathrm{CD}^{+}$suppression is specific to HIV replication [18].

The analysis of viral transcript elongation (including splicing) was extended further along the HIV genome to test for possible amplification of smaller effects downstream from those potentially present at shorter distances from the start of virus transcription. Fig. (5) shows the viral cDNA copy number measured at $3 \mathrm{~kb}, 7 \mathrm{~kb}$, and $9.7 \mathrm{~kb}$ from the start of transcription for each of the four experimental conditions (from the same set of samples examined in Fig. (4)). The fold difference between the suppressed and nonsuppressed viral cultures were determined by quantifying cDNA copy numbers using real-time PCR and then controlling for differences observed at transcriptional initiation. As was expected, the HIV short transcript (119 bp) was the most prominent in copy number in both non-suppressed (positive control) and suppressed systems. Based on the ratio NSS/NSL [non-suppressed short/ non-suppressed long viral RNA transcripts], which measures the progression from initiation [HIV short] to elongation (HIV long-3 kb), on average there are 3.8 times as many HIV short transcripts than 3 $\mathrm{kb}$ transcripts in positive controls $(\mathrm{N}=16)$. The addition of 
JR HVS CD8 ${ }^{+}$and HS HVS CD8 ${ }^{+}$effector cells to infected $\mathrm{CD}^{+} \mathrm{T}$ lymphocytes resulted in greater HIV short to $3 \mathrm{~kb}$ ratios, however, this was to a lesser degree, 2.9 and 2.1 , respectively $(\mathrm{N}=16$ and $\mathrm{N}=12)$. There were fewer $3 \mathrm{~kb}$ copies than $7 \mathrm{~kb}$ or $9.7 \mathrm{~kb}$ copies in all samples tested and this was interpreted to be a consequence of the alternative splicing of HIV-1 transcripts.

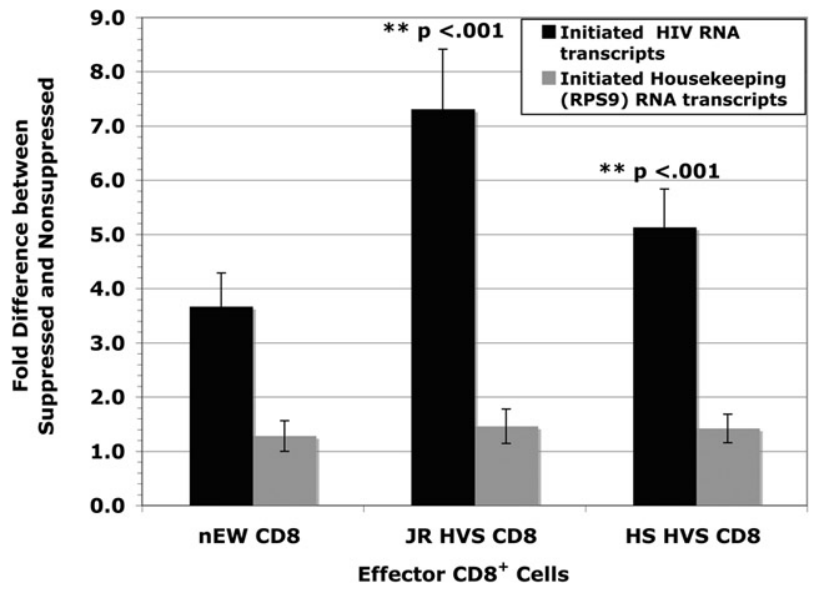

Fig. (3). Reduction in Initiation of Transcription during Noncytolytic $\mathrm{CD}^{+} \mathrm{T}$ cell mediated Suppression of HIV Replication. Both JR-HVS and HS-HVS significantly suppressed viral transcription initiation more than the HIV naïve $\mathrm{CD}^{+} \mathrm{T}$ cells $\left(\mathrm{nEW} \mathrm{CD} 8^{+}\right), \mathrm{p}<$ 0.001 for both comparisons, Student t-Test. The fold difference between the suppressed and nonsuppressed viral cultures were determined by quantifying cDNA copy numbers from the short RNA transcripts using real time PCR.

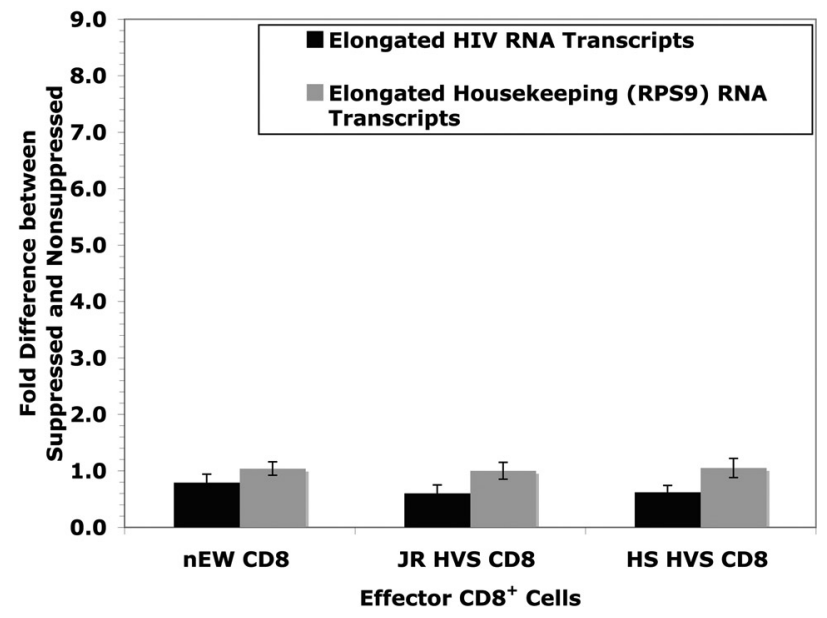

Fig. (4). Transcriptional Elongation/Splicing during Noncytolytic CD8 T cell mediated Suppression of HIV Replication. Using the derived equation [NSL/[SL $x$ [NSS/SS]], this figure illustrates the calculated elongation/splicing effects from non-cytolytic $\mathrm{CD} 8^{+}$ suppression as determined by the "fold difference between suppressed and non-suppressed" viral cultures. By accounting for inhibition at transcriptional initiation, ratio values of $\mathrm{JR}=0.6, \mathrm{HS}=$ $0.6, \mathrm{EW}=0.8$ indicate the likely absence of suppression at elongation and/or splicing $(\mathrm{N}=16, \mathrm{~N}=12$, and $\mathrm{N}=16$, respectively).

Comparing the ratios of the HIV short transcript to either the $7 \mathrm{~kb}$ transcript or the $9.7 \mathrm{~kb}$ transcript, there was no dif- ference between ratios for the positive controls and the $\mathrm{CD} 8^{+}$ $\mathrm{T}$ cell effectors. These data provide evidence that the inhibition of viral replication by noncytolytic $\mathrm{CD} 8^{+}$suppression did not likely involve transcriptional elongation or splicing, but occurred predominately at the initiation of viral transcription.

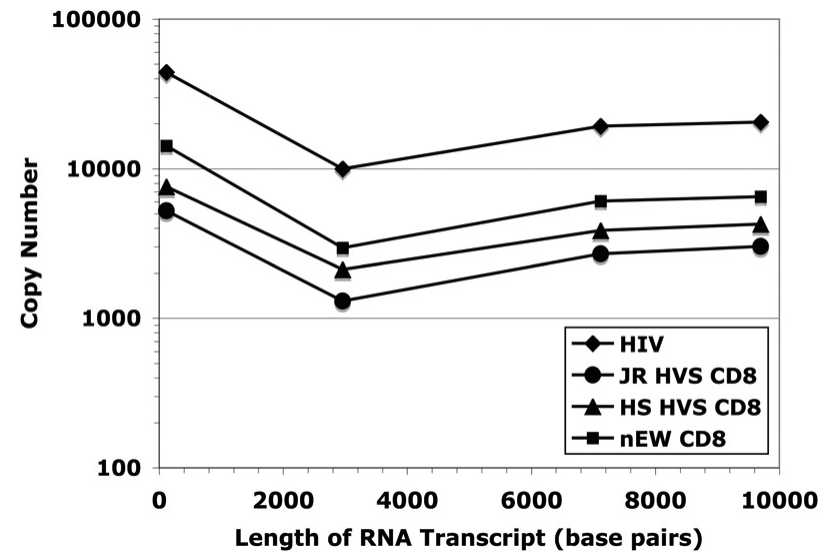

Fig. (5). No significant Effects Past Initiation Regardless of Length of Viral RNA Transcript. The viral cDNA copy number was measured at four distances from the start of transcription for each of the four experimental conditions. When comparing copy number ratios, there is no significant difference (Student t-Test, $\mathrm{p}=0.331$ to $\mathrm{p}=0.476$ ) when comparing HIV short: $7 \mathrm{~kb}$ and HIV short: $9.7 \mathrm{~kb}$ transcript ratios in the positive controls $v s$ suppressed systems (JR HVS $\mathrm{CD}^{+}$, HS HVS $\mathrm{CD}^{+}$) and $\mathrm{nEW} \mathrm{CD}^{+}$. Regardless of the length of the transcript examined, there are no significant effects downstream of initiation.

\section{DISCUSSION}

Here, it is reported that noncytolytic $\mathrm{CD} 8^{+}$suppression of HIV replication is specific to the initiation phase of viral transcription. Previous studies demonstrated the involvement of HIV transcription [18, 19], but did not measure the distinct molecular steps of transcription: initiation and elongation. Expression of HIV-1 genes and inhibition by noncytolytic $\mathrm{CD}^{+}$suppression begins to occur by 17-25 hours after infection [21]. By choosing to evaluate suppression at the 48-hour time point, basal and/or tat-mediated transcription occurred and were possible targets, while $\mathrm{CD}^{+}$suppression was still in an optimal phase.

HIV-1 transcription is regulated by a complex interaction of cellular and viral proteins. Sequences within the HIV-1 genome that are involved in viral gene transcription can be divided into the core promoter elements, the enhancer, the modulatory and negative regulatory elements and the tat responsive element (TAR). HIV transcription is primarily regulated by the viral promoter ( $5^{\prime}$ long terminal repeat) which contains a canonical RNA polymerase II (RNAPII) TATA box, transcription factor binding sites and an initiator element [29]. Subsequent to the initiation of transcription, elongation occurs by competent RNAPII complexes. During transcriptional activation, the viral transactivator, Tat [30], binds to a viral RNA structure, the trans-activation response element (TAR) to increase the level of transcription by greater than 2-logs $[31,32]$. Positive transcription elongation factor $b(\mathrm{P}-\mathrm{TEFb})$, Tat and TAR form a trimeric complex that via one of P-TEFb's components, CDK9 (a CTD 
kinase), phosphorylates the C-terminal heptapeptide repeate domain (CTD), of the largest subunit of RNAPII. Phosphorylation of CTD is thought to mediate the increase in transcript elongation.

Our work suggests that anti-viral CD8 T cells may suppress the transition from the initiation of viral transcripts to elongation of these same transcripts. The mechanisms and factors that could be involved include the alteration of CTD phosphorylation sites or modulation of Tat activities. Tat is primarily thought to be involved in transcriptional elongation, but several labs have presented evidence that Tat is likely to be involved in initiation by aiding in the assembly of the transcription complex (TC) (reviewed in [33]). Understanding whether anti-viral $\mathrm{CD}^{+} \mathrm{T}$ cells act to modulate Tat activity to inhibit HIV replication will be important to consider as potential pathways for the inhibition of viral transcriptional initiation are explored.

Although the data generated here do not support $\mathrm{CD}^{+}$ suppressive activity at elongation and/or splicing, it is important to note that this possibility cannot be fully eliminated. The role of C-terminal heptapeptide repeat domain (CTD) of RNAP II, CA150 and/or the Tat-P-TEFb complex (which includes cyclin T1) has yet to be fully investigated for their potential roles in inhibition of HIV.

There is some controversy as to the ability of HIV-naïve $\mathrm{CD}^{+}$cells to suppress HIV infection. It is reported here that HIV-naïve $\mathrm{CD}^{+}$cells inhibit transcriptional initiation of $\mathrm{HIV}$, but the magnitude is less than that of the $\mathrm{CD}^{+} \mathrm{T}$ lymphocytes derived from long-term nonprogressors. This is in agreement with the lower level of suppression of virus infection by these HIV-naïve $\mathrm{CD}^{+} \mathrm{T}$ cells observed here. We can not exclude the possibility that the transformation of the $\mathrm{CD}^{+}$lymphocytes may have contributed to the transcriptional effects demonstrated here, although we consider it unlikely as previous work by our group demonstrated that the transformed cells recapitulated the phenotype of the primary cells from which they were derived [24].

In the system presented here both soluble and contact mediated non-cytolytic $\mathrm{CD}^{+}$cell suppression of viral replication are permissible. Previous studies have shown that $\mathrm{CD}^{+} \mathrm{T}$ lymphocytes express and secrete soluble molecules capable of suppressing viral replication. The most notable of these molecules are the natural ligands for the CCR5 coreceptors, the $\beta$-chemokines RANTES, MIP- $1 \alpha$ and MIP- $1 \beta$, which do in fact inhibit viral replication by blocking viral entry. Since their discovery, however, several groups have shown that these soluble anti-viral factors cannot adequately explain the viral suppressive activity of $\mathrm{CD}^{+} \mathrm{T}$ cells [34, 35]. Here we report that the anti-viral suppression occurs during transcriptional initiation of the HIV viral life cycle (using X4-tropic virus) and this will further ongoing studies into the precise molecules involved in suppressing viral transcriptional initiation.

Other than HIV-1, Hepatitis B virus is another virus described as sensitive to non-cytolytic $\mathrm{CD}^{+}$cell suppression activity [36]. The use of tat-mediated enhancement of viral transcription is a characteristic that differentiates HIV transcription from Hepatitis B transcription. HIV and Hepatitis B are both inhibited by non-cytolytic $\mathrm{CD}^{+} \mathrm{T}$ lymphocyte suppression as both also use host cell transcriptional machinery for transcription of viral RNA. Considering that HIV utilizes a unique means of enhancing transcription through the HIV tat-protein and TAR-sequence (tat-activating region), and both HIV and Hepatitis B virus use host cell transcription machinery, non-cytolytic $\mathrm{CD}^{+}$suppression could be mediated by altering host cell transcription machinery that may act specifically in concert to target viral transcription. This idea is further supported by the complexity of cellular transcription and the numerous possible targets for modification by host cell defense mechanisms.

As provided in this report, the use of an ex vivo system provides strong data showing that $\mathrm{CD}^{+} \mathrm{T}$ cell suppression occurs at viral transcription. Future studies will focus on in vitro transcription and protein expression analysis to identify the molecular players. This discovery may provide some insight into how $\mathrm{CD}^{+} \mathrm{T}$ cells from long-term nonprogressors and exposed uninfected individuals may suppress HIV replication. Further uncovering of the exact mechanism around the initiation of viral transcription may lead to the development of novel therapeutics for HIV infection or innovative means to elicit this $\mathrm{CD}^{+}$activity as part of a vaccine strategy.

\section{ACKNOWLEDGEMENTS}

We acknowledge the contributions of the Faculty, Staff and Patients of the Duke Adult Infectious Diseases Clinic and the normal blood donors who contributed to this study. We also thank Dr. Simon Lacey for the $\mathrm{CD}^{+} \mathrm{T}$ cell lines, Derrick Goodman for technical assistance and Dr. Xiaoying Shen, Dr. Kent Weinhold and members of the Duke Center for AIDS Research (CFAR) for helpful discussions.

The following reagents were obtained through the NIH AIDS Research and Reference Reagent Program, Division of AIDS, NIAID, NIH: pNL4-3.LUC.R ${ }^{-} E^{-}$from Dr. Nathaniel Landau; U87.CD4, U87.CD4.CCR5 and U87.CD4.CXCR4 from Drs. HongKui Deng and Dan Littman.

This work was supported by National Institute of Allergy and Infectious Disease Grant R01-AI-052779 from the National Institutes of Health.

\section{REFERENCES}

[1] Walker CM, Moody DJ, Stites DP, Levy JA. CD8+ lymphocytes can control HIV infection in vitro by suppressing virus replication. Science 1986; 234(4783): 1563-6.

[2] Mackewicz CE, Garovoy MR, Levy JA. HLA compatibility requirements for CD8+-T-cell-mediated suppression of human immunodeficiency virus replication. J Virol 1998; 72(12): 10165-70.

[3] Walker CM, Erickson AL, Hsueh FC, Levy JA. Inhibition of human immunodeficiency virus replication in acutely infected CD4+ cells by CD8+ cells involves a noncytotoxic mechanism. J Virol 1991; 65(11): 5921-7.

[4] Toso JF, Chen CH, Mohr JR, et al. Oligoclonal CD8 lymphocytes from persons with asymptomatic human immunodeficiency virus (HIV) type 1 infection inhibit HIV-1 replication. J Infect Dis 1995; 172(4): 964-73.

[5] Mackewicz C, Levy JA. CD8+ cell anti-HIV activity: nonlytic suppression of virus replication. AIDS Res Hum Retroviruses 1992; 8(6): 1039-50

[6] Tomaras GD, Greenberg ML. CD8+ T cell mediated noncytolytic inhibition of human immunodeficiency virus type I. Front Biosci 2001; 6: D575-98.

[7] Brinchmann JE, Gaudernack G, Vartdal F. CD8+ T cells inhibit HIV replication in naturally infected CD4+ T cells. Evidence for a soluble inhibitor. J Immunol 1990; 144(8): 2961-6. 
[8] Blackbourn DJ, Mackewicz CE, Barker E, et al. Suppression of HIV replication by lymphoid tissue $\mathrm{CD} 8+$ cells correlates with the clinical state of HIV-infected individuals. Proc Natl Acad Sci USA 1996; 93(23): 13125-30.

[9] Cao Y, Qin L, Zhang L, Safrit J, Ho DD. Virologic and immunologic characterization of long-term survivors of human immunodeficiency virus type 1 infection. N Engl J Med 1995; 332(4): 201-8.

[10] Barker E, Bossart KN, Levy JA. Primary CD8+ cells from HIVinfected individuals can suppress productive infection of macrophages independent of beta-chemokines. Proc Natl Acad Sci USA 1998; 95(4): 1725-9.

[11] Landay AL, Mackewicz CE, Levy JA. An activated CD8+ T cell phenotype correlates with anti-HIV activity and asymptomatic clinical status. Clin Immunol Immunopathol 1993; 69(1): 106-16.

[12] Stranford SA, Skurnick J, Louria D, et al. Lack of infection in HIV-exposed individuals is associated with a strong CD8+ cell noncytotoxic anti-HIV response. Proc Natl Acad Sci USA 1999; 96(3): 1030-5.

[13] Skurnick JH, Palumbo P, DeVico A, et al. Correlates of nontransmission in US women at high risk of human immunodeficiency virus type 1 infection through sexual exposure. J Infect Dis 2002; 185(4): 428-38.

[14] Dragic T, Litwin V, Allaway GP, et al. HIV-1 entry into CD4+ cells is mediated by the chemokine receptor CC- CKR-5. Nature 1996; 381(6584): 667-73.

[15] Amara A, Gall SL, Schwartz O, et al. HIV coreceptor downregulation as antiviral principle: SDF-1alpha- dependent internalization of the chemokine receptor CXCR4 contributes to inhibition of HIV replication. J Exp Med 1997; 186(1): 139-46.

[16] Trkola A, Paxton WA, Monard SP, et al. Genetic subtypeindependent inhibition of human immunodeficiency virus type 1 replication by CC and CXC chemokines. J Virol 1998; 72(1): 396404.

[17] Garzino-Demo A, Arya SK, Devico AL, Cocchi F, Lusso P, Gallo RC. C-C chemokine RANTES and HIV long terminal repeatdriven gene expression. AIDS Res Hum Retroviruses 1997; 13(16): 1367-71.

[18] Chen CH, Weinhold KJ, Bartlett JA, Bolognesi DP, Greenberg ML. CD8+ T lymphocyte-mediated inhibition of HIV-1 long terminal repeat transcription: a novel antiviral mechanism. AIDS Res Hum Retroviruses 1993; 9(11): 1079-86.

[19] Mackewicz CE, Blackbourn DJ, Levy JA. CD8+ T cells suppress human immunodeficiency virus replication by inhibiting viral transcription. Proc Natl Acad Sci USA 1995; 92(6): 2308-12.

[20] Copeland KF, McKay PJ, Rosenthal KL. Suppression of activation of the human immunodeficiency virus long terminal repeat by CD8+ T cells is not lentivirus specific. AIDS Res Hum Retroviruses 1995; 11(11): 1321-6.

[21] Tomaras GD, Lacey SF, McDanal CB, Ferrari G, Weinhold KJ, Greenberg ML. CD8+ T cell-mediated suppressive activity inhibits
HIV-1 after virus entry with kinetics indicating effects on virus gene expression. Proc Natl Acad Sci USA 2000; 97(7): 3503-8.

[22] Mackewicz CE, Patterson BK, Lee SA, Levy JA. CD8+ cell noncytotoxic anti-human immunodeficiency virus response inhibits expression of viral RNA but not reverse transcription or provirus integration. J Gen Virol 2000; 81: 1261-4.

[23] Srivastava KK, Fernandez-Larsson R, Zinkus DM, Robinson HL. Human immunodeficiency virus type 1 NL4-3 replication in four T-cell lines: rate and efficiency of entry, a major determinant of permissiveness. J Virol 1991; 65(7): 3900-2.

[24] Lacey SF, Weinhold KJ, Chen CH, McDanal C, Oei C, Greenberg ML. Herpesvirus saimiri transformation of HIV type 1 suppressive CD8+ lymphocytes from an HIV type 1-infected asymptomatic individual. AIDS Res Hum Retroviruses 1998; 14(6): 521-31.

[25] He J, Choe S, Walker R, Di Marzio P, Morgan DO, Landau NR. Human immunodeficiency virus type 1 viral protein $\mathrm{R}$ [Vpr] arrests cells in the G2 phase of the cell cycle by inhibiting p34cdc2 activity. J Virol 1995; 69(11): 6705-11.

[26] Connor RI, Chen BK, Choe S, Landau NR. Vpr is required for efficient replication of human immunodeficiency virus type-1 in mononuclear phagocytes. Virology 1995; 206(2): 935-44.

[27] Bjorndal A, Deng H, Jansson M, et al. Coreceptor usage of primary human immunodeficiency virus type 1 isolates varies according to biological phenotype. J Virol 1997; 71(10): 7478-87.

[28] Sune C, Garcia-Blanco MA. Transcriptional cofactor CA150 regulates RNA polymerase II elongation in a TATA-box-dependent manner. Mol Cell Biol 1999; 19(7): 4719-28.

[29] Jones KA, Peterlin BM. Control of RNA initiation and elongation at the HIV-1 promoter. Annu Rev Biochem 1994; 63: 717-43.

[30] Arya SK, Guo C, Josephs SF, Wong-Staal F. Trans-activator gene of human T-lymphotropic virus type III (HTLV-III). Science 1985; 229(4708): 69-73.

[31] Cullen BR. Trans-activation of human immunodeficiency virus occurs via a bimodal mechanism. Cell 1986; 46(7): 973-82.

[32] Berkhout B, Silverman RH, Jeang K. Tat trans-activates the human immunodeficiency virus through a nascent RNA target. Cell 1989; 59: 273-282.

[33] Brady J, Kashanchi F. Tat gets the "green" light on transcription initiation. Retrovirology 2005; 2: 69.

[34] Rubbert A, Weissman D, Combadiere C, et al. Multifactorial nature of noncytolytic CD8+ T cell-mediated suppression of HIV replication: beta-chemokine-dependent and -independent effects. AIDS Res Hum Retroviruses 1997; 13(1): 63-9.

[35] Paliard X, Lee AY, Walker CM. RANTES, MIP-1 alpha and MIP1 beta are not involved in the inhibition of HIV-1SF33 replication mediated by CD8+ T-cell clones. Aids 1996; 10(12): 1317-21.

[36] Guidotti LG, Chisari FV. Noncytolytic control of viral infections by the innate and adaptive immune response. Annu Rev Immunol 2001; 19: 65-91. 